\title{
Two-portal video-assisted colopexy in the treatment of intussusception and prolapse of the descending colon in a lamb
}

\author{
Bernardo Nascimento ANTUNES ${ }^{1)}$, Henrique Jonatha TAVARES'), \\ Marta Lizandra LEAL ${ }^{3)}$, João Pedro Scussel FERANTI') and Maurício Veloso BRUN ${ }^{1 \text { )* }}$ \\ ${ }^{1)}$ Department of Small Animal Clinics, Center of Rural Science, Federal University of Santa Maria (UFSM), \\ Roraima Av., 1000, 97105-900, Camobi, Rio Grande do Sul State, Brazil \\ 2)Large Animal Clinics, University Center Ritter dos Reis (UniRitter), Manoel Elias Av., 2001, 91240-260, \\ Porto Alegre, Rio Grande do Sul State, Brazil \\ 3) Department of Large Animal Clinics, Center of Rural Science, Federal University of Santa Maria (UFSM), \\ Roraima Av., 1000, 97105-900, Camobi, Rio Grande do Sul State, Brazil
}

\section{J. Vet. Med. Sci.}

82(7): 967-970, 2020

doi: 10.1292/jvms.19-0409

Received: 24 July 2019 Accepted: 13 May 2020

Advanced Epub: 2 June 2020
ABSTRACT. A lamb presented with recurrent prolapse of the descending colon. On clinical examination, intussusception of the descending colon with the prolapse of a segment was verified. The external anal sphincter had a rupture, extending to the lacerated wound in the anus. The lamb underwent colopexy with the two-portal video-assisted incisional technique and was discharged 6 days after the surgical procedure with a satisfactory clinical outcome. There were no recurrences or complications for at least 9 months. Video-assisted colopexy is an alternative treatment for intussusception and recurrent colon prolapse in sheep, even in the presence of an external anal sphincter rupture.

KEY WORDS: caudectomy, laparoscopy, reconstructive surgery, ruminant, soft tissue surgery

Rectal prolapse involving protrusion of the mucosa through the anus was described in sheep in $1500 \mathrm{BC}$ [4]. According to the literature, approximately $2-10 \%$ of lambs up to 1 year of age are affected by rectal prolapse, which can potentially result in shock and death if a large part of the intestinal tract is expelled [6]. All layers or only the mucosa may be involved in the prolapse, classified as total and partial prolapse, respectively [7]. The literature reveals that the chances of rectal prolapse in sheep are greater when their tails are cut short.

In the same species, the indicated treatment is manual reduction and a temporary purse string suture [5], in addition to the perianal injection of $1 \mathrm{ml}$ of oxytetracycline along the rectal wall for lambs [6]. Resection and anastomosis are more often reported in the treatment for dogs in cases when tissue of the prolapsed segment is devitalized [1].

In dogs, studies on the video-assisted colopexy technique with two access portals have been reported [3], being the method of choice for colopexy in this species. Laparoscopic techniques in ovine and caprine animals are more commonly used as a reproductive tool, although they are still an alternative method of diagnosis, referred to as exploratory laparotomy [4]. To the best of our knowledge, there have been no reports of the video-assisted colopexy technique in ovine animals. Therefore, the present study reports the video-assisted colopexy procedure using two access portals in the treatment of recurrent colon intussusception and prolapse in a Texel breed lamb.

A 1-year-old, intact male Texel lamb, weighing $53 \mathrm{~kg}$, with an apparent prolapsed rectum (Fig. 1A) for 6 days was sent to the University Veterinary Hospital of the Federal University of Santa Maria (HVU-UFSM). The animal had received native pasture and white oats as feed. When young, the animal was subjected to caudectomy, and only the first coccygeal vertebra was retained. The presence of myiasis in the ventral portion of the anus before prolapse was noted, and treatment for both conditions was initiated at the animal's original location, without a purse string suture and with recurrence of prolapse and laceration of the ventral wound caused by myiasis. No similar cases were reported in the flock.

On clinical examination, viability of the rectal mucosa was verified through coloring and palpation (friability and tissue peeling). A cul-de-sac between the exposed mucosa and the external anal sphincter, which was ruptured, was palpated, indicating intussusception with a prolapse of the descending colon. The animal's cardiac and respiratory rates were elevated, and ruminal motility had decreased.

*Correspondence to: Brun, M. V.: mauriciovelosobrun@hotmail.com (National Council for Scientific and Technological Development-CNPqBrazil fellowship (305876/2018-0))

O2020 The Japanese Society of Veterinary Science

This is an open-access article distributed under the terms of the Creative Commons Attribution Non-Commercial No Derivatives (by-nc-nd) License. (CC-BY-NC-ND 4.0: https://creativecommons.org/licenses/by-nc-nd/4.0/) 

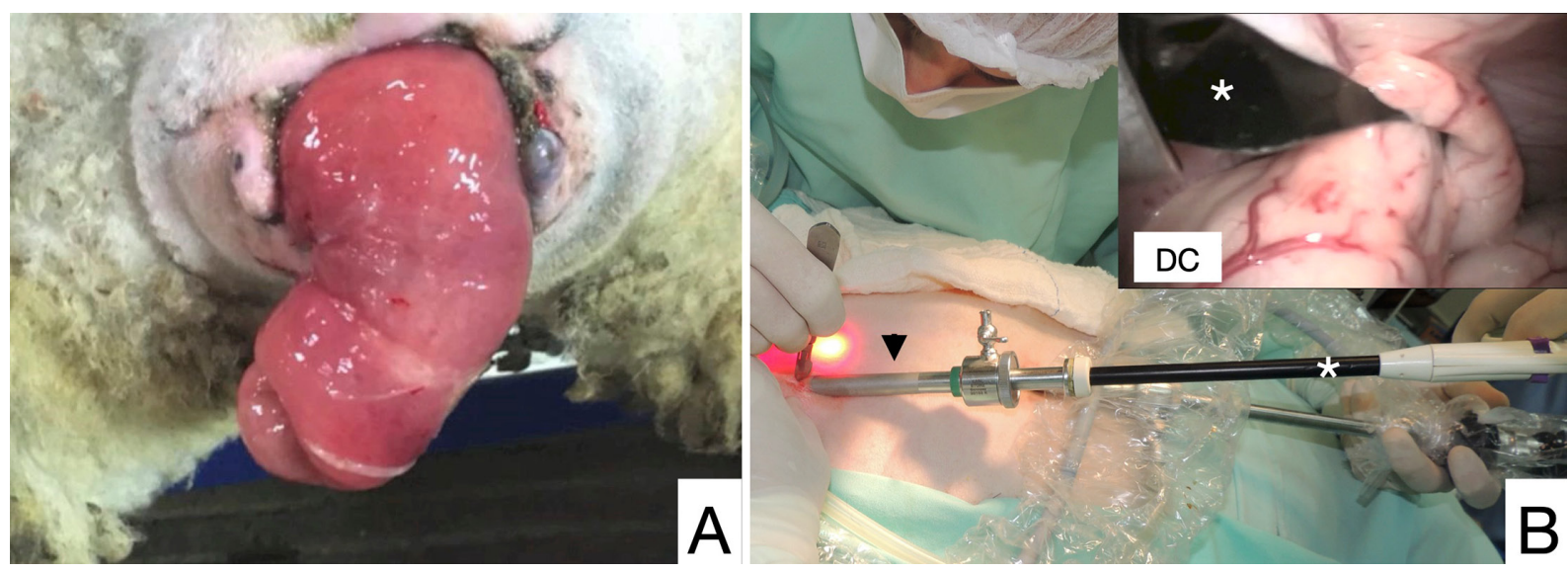

Fig. 1. Images of video-assisted colopexy in a sheep. (A) Intussusception and prolapse of the rectum and descending colon. (B) Seizure and traction of the descending colon (DC) with a Babcock forceps $(*)$ through the second portal (arrow head). Wound enlargement of the second access in order to exteriorize the descending colon.

During the first 10 days of hospitalization, two supporting purse string sutures (nylon 0 suture) were applied around the anus, and manual reduction of the prolapse was performed. After removal of the sutures, the prolapse recurred, and surgical treatment with two-portal video-assisted colopexy was chosen. To avoid ischemia of the prolapsed intestinal segment, the prolapse was manually reduced. Subsequently, three large support sutures between the lateral borders of the anal wound were applied using a polypropylene 2 suture in a horizontal mattress pattern, capped with a Foley probe (Latex Foley Catheter Silicone Coated, 18-Fr; Well Lead ${ }^{\circledR}$, Guangzhou, China). The suture was removed after 4 days and prior to surgery.

Scopolamine $(0.38 \mathrm{mg} / \mathrm{kg}$, orally, thrice a day) was administered 1 day before and after surgery, along with penicillin $\mathrm{G}$ benzathine (40,000 IU/kg, intramuscular [IM]), meloxicam $(0.5 \mathrm{mg} / \mathrm{kg}, \mathrm{IM})$, and dexamethasone $(0.35 \mathrm{mg} / \mathrm{kg}$, IM), once a day for 2 days before surgery.

The lamb presented with hematocrit of $18 \%$ and serum albumin of $1.5 \mathrm{~g} / \mathrm{d} l$ in the preoperative period. Blood transfusion with $450 \mathrm{ml}$ of blood from a compatible donor, as determined by cross-match tests, was performed during the intraoperative and immediate postoperative periods.

The hair was clipped from the operative area and following $27 \mathrm{hr}$ of solid-food fasting, the lamb received $\mathrm{ketamine}(8 \mathrm{mg} / \mathrm{kg}$, IM), midazolam $(0.5 \mathrm{mg} / \mathrm{kg}, \mathrm{IM})$, and tramadol $(4 \mathrm{mg} / \mathrm{kg}, \mathrm{IM})$ as preanesthetic medications, and general anesthesia was induced with propofol (4 mg/kg, intravenously). The lamb was intubated using a rigid endoscope $\left(4.8 \mathrm{~mm} \times 29 \mathrm{~cm} 25^{\circ}\right.$, unreadable mark). Anesthesia was maintained with isoflurane vaporized in $100 \% \mathrm{O}_{2}$ in a closed system of total gas rebreathing and mechanical ventilation (13 movements/min) throughout the procedure.

With the patient in dorsal recumbency, antisepsis of the surgical areas was carried out with an aqueous solution of chlorhexidine $4 \%$, followed by an alcoholic solution of chlorhexidine $0.2 \%$. After preparation of the surgical areas, a cutaneous incision of 12 $\mathrm{mm}$ was made in the left paramedian line, approximately $3.5 \mathrm{~cm}$ from the midline and caudal to the prepuce, for an endoscopic access to the abdominal cavity through the placement of the first portal (11 mm, Karl Storz Endoscopy ${ }^{\circledR}$, Tuttlingen, Germany), thereby creating a pneumoperitoneum with heated medical $\mathrm{CO}_{2}$ at a pressure of $12 \mathrm{mmHg}$.

After inspection of the abdominal cavity with a $10-\mathrm{mm}$ endoscope $\left(10 \mathrm{~mm} \times 33.5 \mathrm{~cm} 0^{\circ}\right.$, Karl Storz Endoscopy $\left.{ }^{\circledR}\right)$ introduced through the first portal, placement of the second portal $\left(11 \mathrm{~mm}\right.$, Karl Storz Endoscopy $\left.{ }^{\circledR}\right)$ was initiated with a laparoscope in the pre-pubic left paramedian region, approximately $12 \mathrm{~cm}$ caudal to the first portal at the same midline distance. The lamb was placed in the steep Trendelenburg position (approximately $9^{\circ}$ ), and a 10-mm video surgical Babcock forceps (Endo Babcock, Auto Suture $^{\circledR}, 10 \mathrm{~mm} \times 35 \mathrm{~cm}$, São Paulo, Brazil) placed through the second portal was used to assist in the identification and traction of the descending colon (Fig. 1B).

A surgical assistant kept the prolapsed tissue reduced using digital pressure, thereby aiding in the exteriorization of the colon segment seized through the second portal, enlarged by approximately $1.5 \mathrm{~cm}$ (Fig. 2A).

With two stay sutures on the segment exposed with descending colon and by passing a 10-mm diameter latex tube inserted into the lumen of the descending colon through the anus and rectum, the orientation of the descending colon was determined (Fig. 2A). Using a No. 15 scalpel blade and Metzenbaum scissors, a seromuscular incision of approximately $2.5 \mathrm{~cm}$ was made on the antimesenteric border of the exposed portion of the descending colon (Fig. 2B). The borders of the colon wound were apposed and sutured to the external lamina of the sheath of the rectus abdominus muscle (second portal access enlarged) by two sutures (medial and lateral) in a simple continuous pattern with 3-0 and 2-0 polypropylene sutures (Fig. 3A).

The two stay sutures were removed, and external layer of the abdominal muscle was sutured in a cruciate pattern with a 0-polyglactin 910 suture, followed by subcutaneous closure in a simple continuous pattern with a $2-0$ polyglactin 910 suture. The abdominal cavity was again inspected, with a reduction of the pneumoperitoneum pressure to $4 \mathrm{mmHg}$. With no complications or significant alterations, the skin was sutured with a 4-0 nylon suture (horizontal mattress pattern) (Fig. 3B). The surgical procedure 

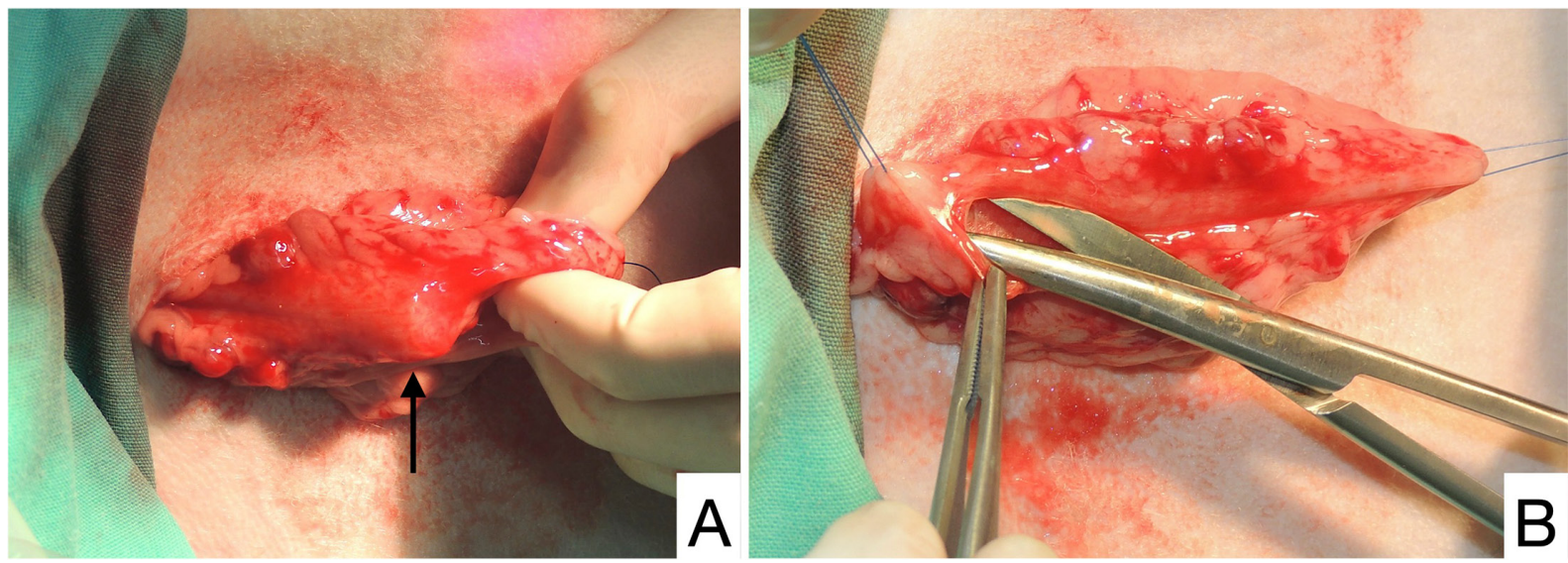

Fig. 2. Images of video-assisted colopexy in a sheep. (A) Identification and position of the exteriorized descending colon segment using a latex tube (arrow) inserted through the anus and rectum. (B) Seromuscular incision of approximately $2.5 \mathrm{~cm}$ on the antimesenteric border of the exposed portion of the descending colon.
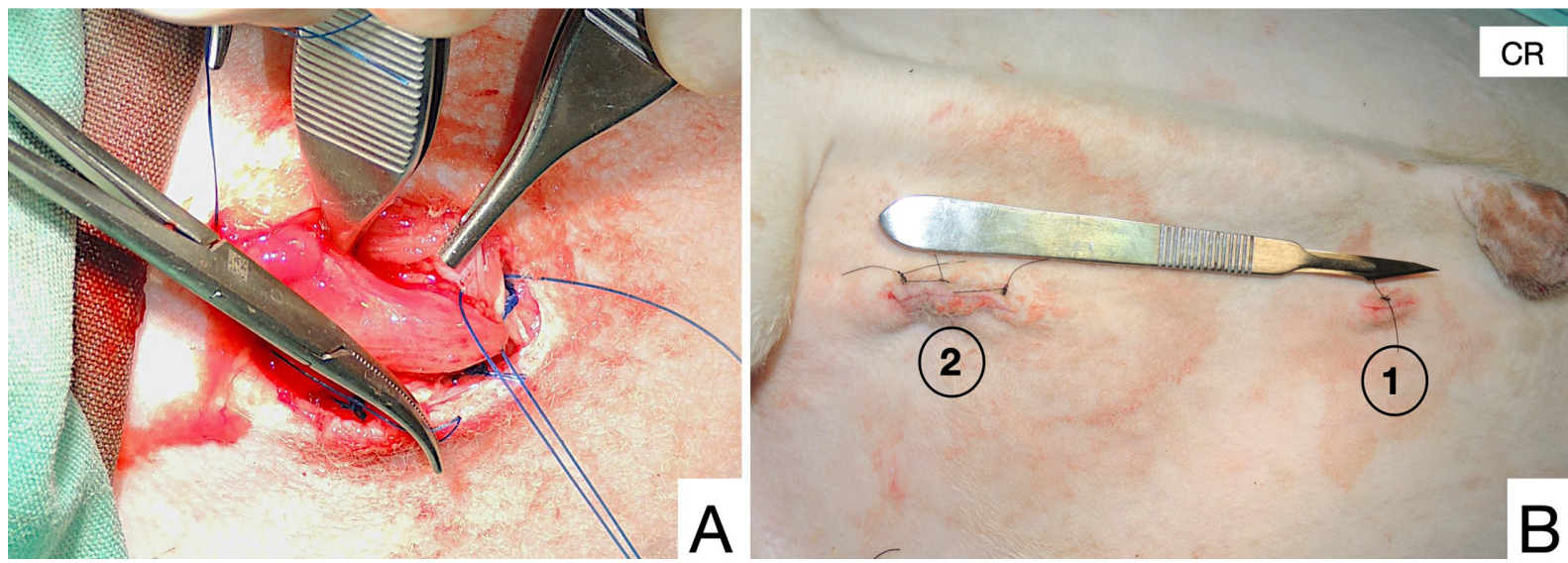

Fig. 3. Images of video-assisted colopexy in a sheep. (A) Suture of the colon wound in the abdominal rectus muscle in order to perform colopexy. (B) Aspect of access wounds (1, wound of positioning the first portal; and 2, wound of accessing the second portal after enlargement) immediately postoperatively considering one No. 3 scalpel handle. $\mathrm{CR}=$ cranial reference.

lasted approximately $30 \mathrm{~min}$, with $60 \mathrm{~min}$ of anesthesia.

The lamb was returned to inpatient care, where blood transfusion was completed and administered with the postoperative medications ceftiofur ( $1.1 \mathrm{mg} / \mathrm{kg}$, IM, every $24 \mathrm{hr}$ for 5 days), meloxicam $(0.5 \mathrm{mg} / \mathrm{kg}$, IM, every $24 \mathrm{hr}$ for $48 \mathrm{hr})$, hyoscine $(0.2$ $\mathrm{mg} / \mathrm{kg}$, IM, every $12 \mathrm{hr}$ for 5 days), dipyrone ( $25 \mathrm{mg} / \mathrm{kg}$, IM, every $12 \mathrm{hr}$ for 5 days), cyanocobalamin ( $250 \mu \mathrm{g} / \mathrm{kg}$, IM, once), and ferric hydroxide $(3.1 \mathrm{mg} / \mathrm{kg}$, IM, once). A sugar-based paste with nitrofurazone for topical application to the lacerated perianal wound was also prescribed.

The 27-hr fasting, as indicated for ovine animals [4], was adequate and allowed for proper emptying of the digestive tract in order to locate and expose the colon. Throughout the anesthetic procedure, the measured cardiopulmonary parameters remained stable. The lamb had a satisfactory clinical outcome and was discharged 6 days after surgery, without recurrence or complications, which are common in conventional colopexy, according to the literature [7]. There were no recurrences in 9 months. However, the lamb developed anorexia after 8 months, which led to death in the 9th month, as reported over the telephone. As no medical care was sought, and necropsy was not performed, it was not possible to determine the cause of death.

Due to the paucity of studies on digestive disorders in small ruminants, knowledge pertaining to other species is often applied to ovine species [4]. However, we also sought the application of a previously described technique for dogs [5] and cats [8] that had demonstrated to be effective in these animals.

Risk factors, such as cough, diarrhea, overweight, and a grain-based diet, were absent in the present case. However, the association of tail amputation with the occurrence of rectal prolapse, as described by the aforementioned author, in addition to the presence of perianal myiasis, contributed to the fragility and subsequent rupture of the ventral region of the anal sphincter in this animal. These conditions favored the occurrence of prolapse and its recurrence after removal of the containment sutures, such as 
the rectal purse string suture.

The incisional technique used in the present case report allowed more permanent fixation of the colon [1]. However, as a potential complication in this procedure, there was a risk for contamination of the cavity resulting from the unintentional perforation of the colon mucosa [8]. In the present case, enlargement of the antimesenteric incision was performed carefully, with the assistance of Metzenbaum scissors. Colopexy in dogs not involving the submucosal layer was associated with reduced maintenance of the fixation of the organ [2]. Thus, we involved the submucosa layer bilaterally.

According to the literature, the success rate for colopexy was higher in animals with less than 2 weeks of prolapse, and these rates decrease drastically from the first recurrence [7]. In order to preserve the viability of the tissue and increase the chances of therapeutic success, the prolapse was reduced on hospitalization day 1 and after the second relapse. With the present report, it can be concluded that the video-assisted colopexy technique with two portals is an alternative treatment for intussusception and recurrent colon prolapse in ovine animals. The technique was shown to be effective even in the presence of an external anal sphincter rupture.

ACKNOWLEDGMENTS. This study was financed in part by the Coordenação de Aperfeiçoamento de Pessoal de Nível SuperiorBrazil (CAPES) (Finance Code 001), Conselho Nacional de Desenvolvimento Científico e Tecnológico (CNPq), and Comissão de Residência Multiprofissional em Saúde (COREMU)-Ministério da Educação (MEC) do Brazil.

\section{REFERENCES}

1. Brun, M. V., Pippi, N. L., Beck, C. A. C., Contesini, E. A., Pereira, R. A., Stedile, R., Bonfada, A. T., Bordin, A. I., Silva, T. F., Columé, L. M., Gomes, K. and Vieira, A. R. P. Junior. 2004. Evaluation of two differents sutures for inciosional laparoscopic colopexy in dogs. A experimental study. Braz. J. Vet. Res. Anim. Sci. 41: 154-161. [CrossRef]

2. Brun, M. V., Pippi, N. L., Beck, C. A. C., Contesini, E. A., Pereira, R. A., Stedile, R., Bonfada, A. T., Columé, L. M., Gomes, K., Vieira, A. R. P. Junior. and Silva, T. F. 2004. Open or laparoscopic assisted transparietal colopexy in dogs. Cienc. Rural 34: 829-837. [CrossRef]

3. Brun, M. V. 2015. Digestive tract surgery. pp. 239-250. In: Small Animal Video Surgery (Brun, M. V. ed.), Guanabara Koogan, Rio de Janeiro.

4. Christine, B. N., Baird, A. N. and Pugh, D. G. 2002. Diseases of the gastrointestinal system. pp. 71-105. In: Sheep and Goat Medicine, 2nd ed. (Pugh, D. G. and Baird, A. N. eds.), Elsevier, Maryland Heights.

5. Guedes, R. L., Linhares, M. T., Castro, I. F. Junior., Simeoni, C. P., Cunha, T. O., Gomes, C., Brun, M. V. and Pippi, N. L. 2012. Two portal videoassisted colopexy for treatment of recurrent rectal prolapse. Cienc. Rural 42: 112-115. [CrossRef]

6. Luther, J. 2008. Causes, prevention and treatment of rectal prolapse in sheep. NDSU Extension Service. AS-1388.

7. Oliveira, G. K., Oliveira, C. K., Raiser, A. G., Silva, S. V. and Mônaco, F. 2009. [Colopexy in Dorper lambs with rectal prolapse] Cienc. Rural 39: 479-483 (in Portuguese). [CrossRef]

8. Popovitch, C. A., Holt, D. and Bright, R. 1994. Colopexy as a treatment for rectal prolapse in dogs and cats: a retrospective study of 14 cases. Vet. Surg. 23: 115-118. [Medline] [CrossRef] 